\title{
Hydrogeological model and hydraulic behaviour of a large landslide in the Italian Western Alps
}

\author{
G. Pisani, M. Castelli, and C. Scavia \\ Department of Structural and Geotechnical Engineering, Politecnico di Torino, Torino, Italy
}

Received: 11 March 2010 - Revised: 25 October 2010 - Accepted: 28 October 2010 - Published: 30 November 2010

\begin{abstract}
A study of the large, deep-seated Rosone landslide (Italian Western Alps) is presented. A large amount of geological and geomechanical data has been collected in this area, due to the presence of various villages and man-made structures, and an automatic monitoring system was installed in December 2000. Since its installation, this system has been showing a continuous slow movement with periodical accelerations that can be correlated to heavy rainfall events. A hydrogeological model has been developed to study the influence of rainfall events on the pore pressure variations inside the rock slope. The structural characteristics, inclinometric and piezometric measurements, statigraphic and seismic profiles, geomorphologic information, water balance and chemical analyses of the main springs in the slope have been taken into account to consider this problem. A numerical hydraulic investigation, based on a continuum equivalent model of the landslide, has then been carried out using the FLAC ${ }^{3 \mathrm{D}}$ computer code. Some preliminary results, which highlight the role of permeability and the porosity values of the rock mass on the pore pressure variations during heavy rainfall, are shown in the paper.
\end{abstract}

\section{Introduction}

The Rosone slope, located on the Italian side of the Western Alps, between the Orco and Piantonetto rivers (Fig. 1), has been affected by recurrent instability phenomena due to a slow deep-seated gravitational slope deformation process (DSGSD), which is well known from historical information (Ramasco et al., 1989). The gravitational deformation is located in the metamorphic rock of the Gran Paradiso Massif and affects an area of $5.5 \mathrm{~km}^{2}$, which ranges from 700 to $2000 \mathrm{~m}$ a.s.l. and reaches great depths (up to $40 \mathrm{~m}$ ).

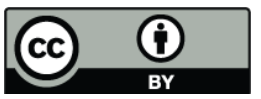

Correspondence to: G. Pisani (gabriele.pisani@polito.it)
Some geomorphological evidence and field investigations (Regione Piemonte and Université J. Fourier, 1996) made it possible to identify the eastern sector of the gravitational deformation (Bertodasco sector, see Fig. 2) as the most likely to undergo a catastrophic evolution. At present, this sector can be considered as active.

Two important inhabited zones are located around the Bertodasco sector (Fig. 2): the village of Rosone Nuovo (built after the evacuation of Bertodasco and Rosone in 1957) and the Turin (City) Electricity Agency (AEM, now IRIDE) $99 \mathrm{MWh}$ hydroelectric power plant. The water, drawn from the Ceresole Reale dam (Fig. 1), reaches some pools through a 17-km-long gallery tank, and falls towards the power plant inside a penstock which covers almost the entire length of the landslide with a drop of $813 \mathrm{~m}$ (Fig. 2). The landslide also involves the N460 National Road from Turin to Ceresole Reale, which runs along the valley bottom.

Due to the presence of these several elements at risk, the Rosone landslide has been thoroughly investigated since 1929, when the power plant facilities were first constructed. Moreover, an automatic monitoring system was installed in 2000. During the last century, the landslide constantly and very slowly continued to move in the eastern part (Bertodasco sector), but in 1953 a paroxysmal incident occurred, when heavy rainfall caused accelerated movements in some localised areas on the active landslide. Another major paroxysmal movement had taken place in the early 18th century, and in 2000 important displacements were also recorded (several centimeters) after heavy rainfall events.

All the analyses carried out led to a collection of geological and geomechanical studies (e.g. Forlati et al., 1991) and to numerical investigations (e.g. Barla and Chiriotti, 1995; Chiriotti, 1997; Forlati et al., 2001; S.G.I., 2001; Bonnard et al., 2004) on the overall behaviour of the landslide which showed that the change in the water table level within the moving mass is probably the main cause of the observed movements. 


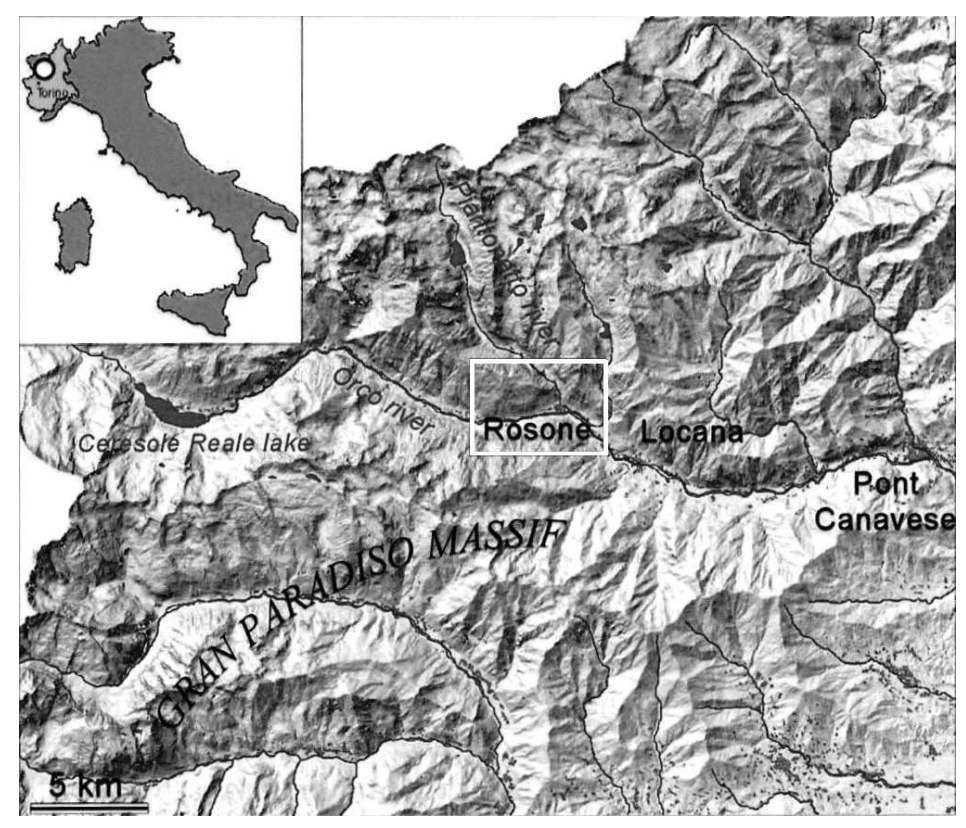

Fig. 1. Location of the Rosone landslide, Orco valley (Italy).

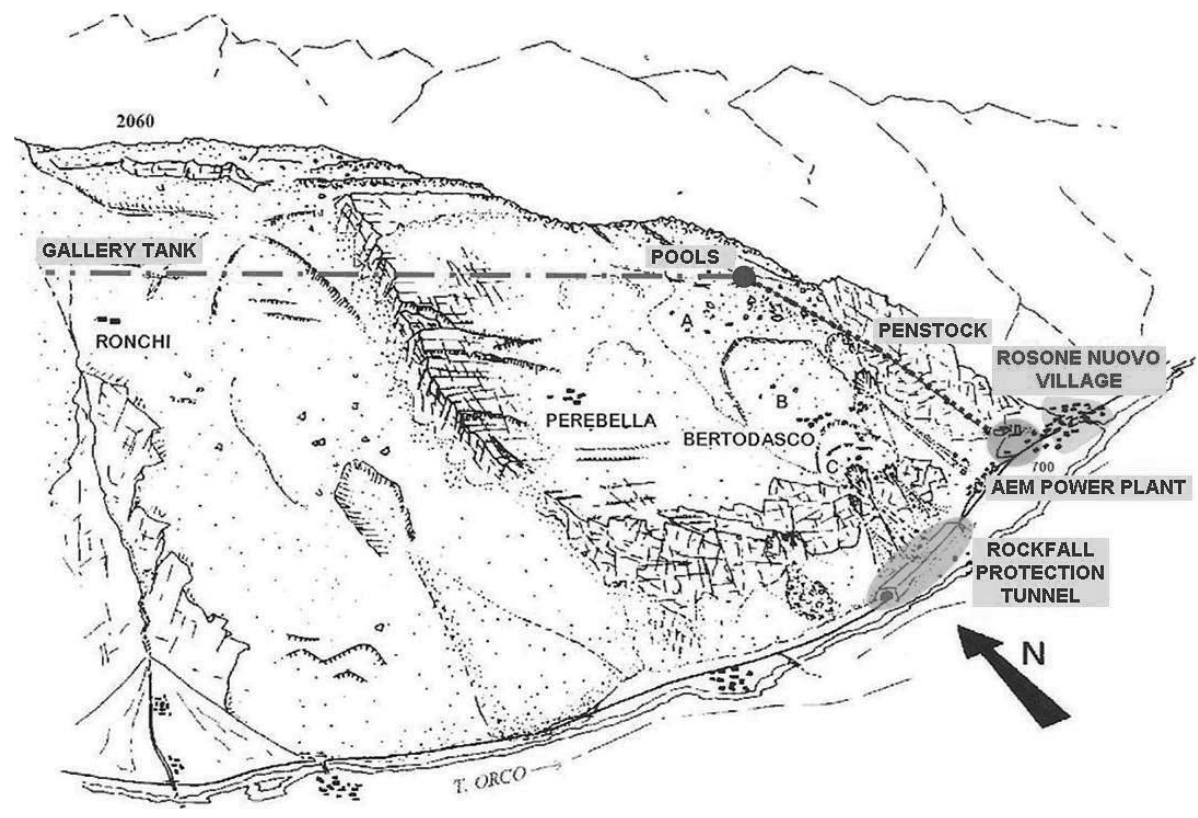

Fig. 2. Sketch of the area affected by the DSGSD process (modified from Regione Piemonte and Université J. Fourier, 1996).

Even though the relationship between the heavy rainfall and the increase in movement is qualitatively clear, it is very difficult to estimate in temporal and quantitative terms, due to the lack of an infiltration model of the massif. This problem has been dealt with by the development of a new hydrogeological model of the Rosone landslide on the basis of field investigations, core observations, chemical analysis and observation of the discharge evolution of the main springs that drain the slope. A series of numerical analyses, based on a continuum equivalent model of the slope, is at present being performed using a simplified version of the hydrogeological model with the aim of back analysing the key hydraulic parameters of the rock mass and numerically simulating the measured pore pressure variations in time. The comprehension of the slope hydrology and the estimation of the equivalent hydraulic parameters of the disrupted rock mass will be of fundamental importance for evaluating the mechanical 
response to the transient fluctuations of the groundwater level in the perspective of understanding the hydromechanics of the slope process and the prediction of future slope movements related to heavy rainfall events.

The studies that have been carried out to define the hydrogeological model of the landslide and the preliminary results of the numerical hydraulic analyses are presented in this paper and some conclusions are drawn concerning further developments.

\section{Landslide description}

The landslide is close to the confluence of two glacial valleys, namely the Orco and Piantonetto valleys, both of which are in the central part of the Gran Paradiso Massif, in the Augen Gneiss Complex.

As described by Forlati et al. (1991) and Regione Piemonte and Université J. Fourier (1996), the morphostructural characteristics of the area suggest subdividing it into three adjacent sectors (Fig. 2), roughly corresponding to the villages of Ronchi, Perebella and Bertodasco, which reflect the final, early and intermediate stages of the evolution of the deep-seated gravitational process, respectively.

Due to the presence of the AEM-IRIDE facilities, the eastern sector of Bertodasco (intermediate stage of evolution) is the most intensely investigated and well known sector. The upper part of this sector has several trenches perpendicular to the main direction of the slope movement, whereas in the middle part it is affected by rotational sliding movements superimposed on general toppling and planar slides.

On the basis of ground reliefs, instrumental measurements, historical interpretations and displacement reconstructions which have been carried out since 1929, the Bertodasco sector has been identified as the most likely to undergo a catastrophic evolution (Regione Piemonte and Université J. Fourier, 1996). For this reason, attention has been focused on this sector, which can be divided into three zones with different degrees of mobility, referred to as A, B and C, going from the top of the valley to the bottom (Fig. 2).

Zone A includes the upper part of the sector, where the movements of the slope and the related morphological evidence have been poorly defined. Although disrupted, this zone still preserves its original structural features, with minor translational movements. In the lower eastern part of this zone, it is possible to recognize more prominent displacements, characterised by wide-open fractures that split the rock mass into blocks of huge dimensions.

Zone B is bordered by a series of prominent curved scarps sub-parallel to the main joint system, some of which opened before the 1953 reactivation of the landslide. The geometry of these scarps is well defined and straight, and corresponds to a 3-4-m downhill movement. Movement in zone B induced the partial translation of the lower eastern part of zone A, the toppling and rolling of large blocks, and caused damage to the AEM-IRIDE power plant facilities.
Zone $\mathrm{C}$, which has been affected by major gravitational movements, is extremely heterogeneous and consists of heterometric disaggregated rock blocks. A huge curved scarp (also recognisable from photo interpretation) separates this zone from zone B (see also Figs. 9 and 11). The upper part of zone $\mathrm{C}$ is affected by movements along many concave and sub-parallel scarps, which determine an abrupt change in the slope morphology. These slow but constant movements and sudden accelerations due to periods of intense rainfall caused a great deal of damage to the Bertodasco village over the last sixty years. The lower part of zone $\mathrm{C}$ is instead affected by rock-debris and debris flows which have partially destroyed the N460 National Road and led to the construction of a rockfall protection tunnel (see Fig. 2).

\section{Hydrogeological model}

The Gran Paradiso massif is made of intensely laminated orthogneiss and augen-gneiss, intercalated with smaller quantities of white micaschists and rare chloritoschists.

The schistosity is locally developed parallel to the chloritoschist layers, which can be interpreted as high strain shear zones created by metamorphic reactions along high pressure mylonitic shear bands (Dal Piaz and Lombardo, 1986). Since the shear strength of these layers is lower than the average values of the Gran Paradiso augen orthogneiss, instability problems can occur when the mean plane of the slope presents the same orientation values as the regional metamorphic schistosity.

A detailed analysis based on photo interpretation and field observations has shown that the apparently different Orco and Piantonetto valley mountainsides have similar geological characteristics.

In both valleys, huge shear zones, sub-parallel to the regional schistosity, separate areas of outwardly massive gneissic rock (see Fig. 3a). However, many less persistent planes, again sub-parallel to the regional schistosity, are also present between these major shear bands and seem to drive not only the deformation process of the metamorphic rock, but also the hydraulic behaviour of the rock mass. Many traces of water can actually be observed on the outcropping on the southern side of the Orco valley (Fig. 3b).

All these observations have allowed us to deduce that the metamorphism of the rock mass and the deformation processes within the shear zones have generated some impermeable layers, made up of chloritoschists and finer materials.

As far as the landslide slope (northern side of the Orco valley) is concerned, these observations would suggest that different unconfined aquifers are separated by some shear bands, which assume the hydraulic role of less permeable layers than the aquifers above. Moreover, from a structural point of view, the shear bands (and the schistosity) have the same orientation as the slope and therefore seem to play 


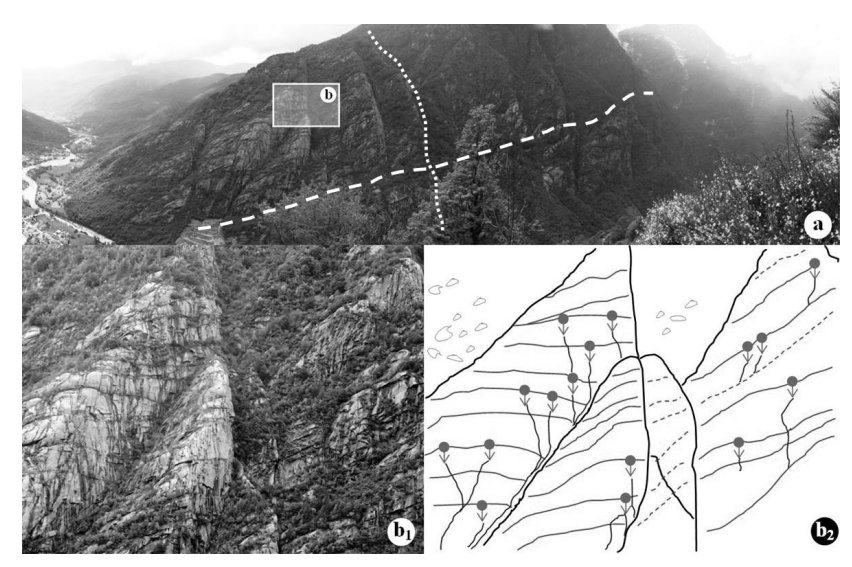

Fig. 3. (a) Southern side of the Orco valley with indication of a major shear zone (dashed line) and a huge N-S striking fault (dotted line); $\left(\mathbf{b}_{1}\right)$ view of the smaller schistosity planes between the major shear zones: traces of water which is drained from these layers are well visible; $\left(\mathbf{b}_{2}\right)$ sketched representation of $\left(b_{1}\right)$.

an active role in both the development of the gravitational deformation and the evolution of the landslide.

With regards to the hydrogeological conditions of the slope, literature data referring to the whole Orco valley (Sacchi et al., 2004) have allowed us to identify two main types of groundwater flow systems:

1. rapid groundwater flow systems, which have mainly developed in the weathered zone of the massif. These flow systems are shallow, with low mineralization, local groundwater recharge, low discharge and electric conductivity;

2. deep groundwater flow systems which are extended at the massif scale. These flow systems are deep and located in the rock basement faults, with high discharge, mineralization degree and electric conductivity.

A census of the springs which drain the Rosone landslide was first performed at the slope scale in the summer 2004, when the water emerging from some of the springs was measured, sampled and chemically analysed (Binet et al., 2007).

The recharge area, defined on the basis of geomorphological considerations, is laterally bordered by the huge N$S$ striking fault that separates the Perebella sector from the Ronchi sector (see Figs. 2 and 6) and its upper and lower boundaries are determined by the crest of the slope and by the lower boundary of zone $\mathrm{C}$, respectively.

The observations made by Binet et al. (2007) have been integrated with new studies on the water chemistry, and on the discharge of the springs; a hydraulic balance of the whole slope has also been drawn up. In addition to perennial water emerging from springs in Bertodasco and Perebella, 16 main perennial springs with major discharges can be found at the toe of the slope or next to the outcrops located at the bottom of zone $\mathrm{C}$ of the Bertodasco sector (see Figs. 6 and 11).
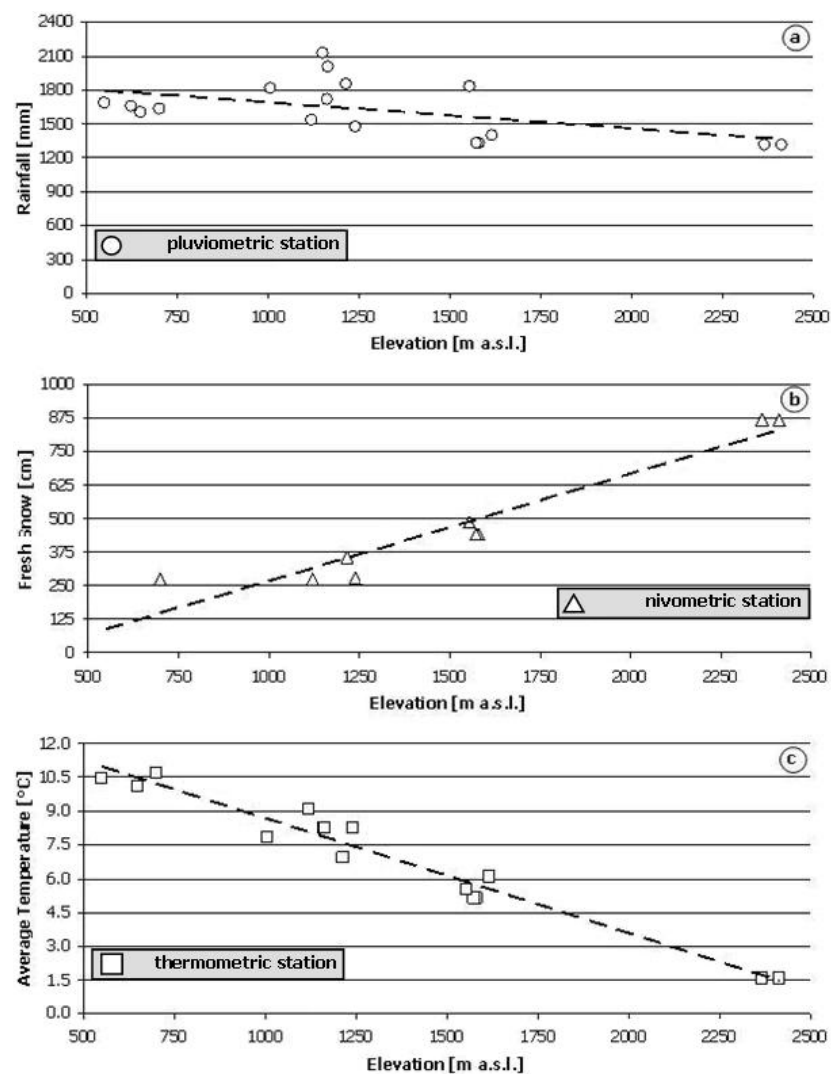

Fig. 4. Correlation of (a) rainfall, (b) fresh snow and (c) temperature versus elevation in the Orco basin (from unvalidated data, ARPA Piemonte personal communication).

The evaluation of the global water budget of the whole slope involved a comparison between the total annual inflow (calculated as the sum of all the contributions which infiltrate the slope) and the total annual outflow (estimated as the sum of the discharges of the 16 main springs that drain the recharge area), both of which were gathered from the hydrometeorological conditions for the year 2008 .

The estimation of the total infiltrated water in the slope during the year 2008 was performed by detracting the amount of evapotranspirated water, evaluated according to the Turc equation (Turc, 1961), from the rainfall and snowfall amounts, the latter of which had first to be transformed into snow water equivalent (SWE) assuming a mean snow density value of $120 \mathrm{~kg} \mathrm{~m}^{-3}$. Meteorological data (rainfall, fresh snow, snow cover, and temperature) from 21 different meteorological stations in the Orco basin were analysed to extrapolate their correlations with the elevation of the stations themselves (Fig. 4).

In order to investigate the presence of independent aquifers, the global recharge area was subdivided into the landslide area (Bertodasco sector) and the Perebella area, whose extensions, mean heights and main spring clustering zones are shown in Fig. 5. 


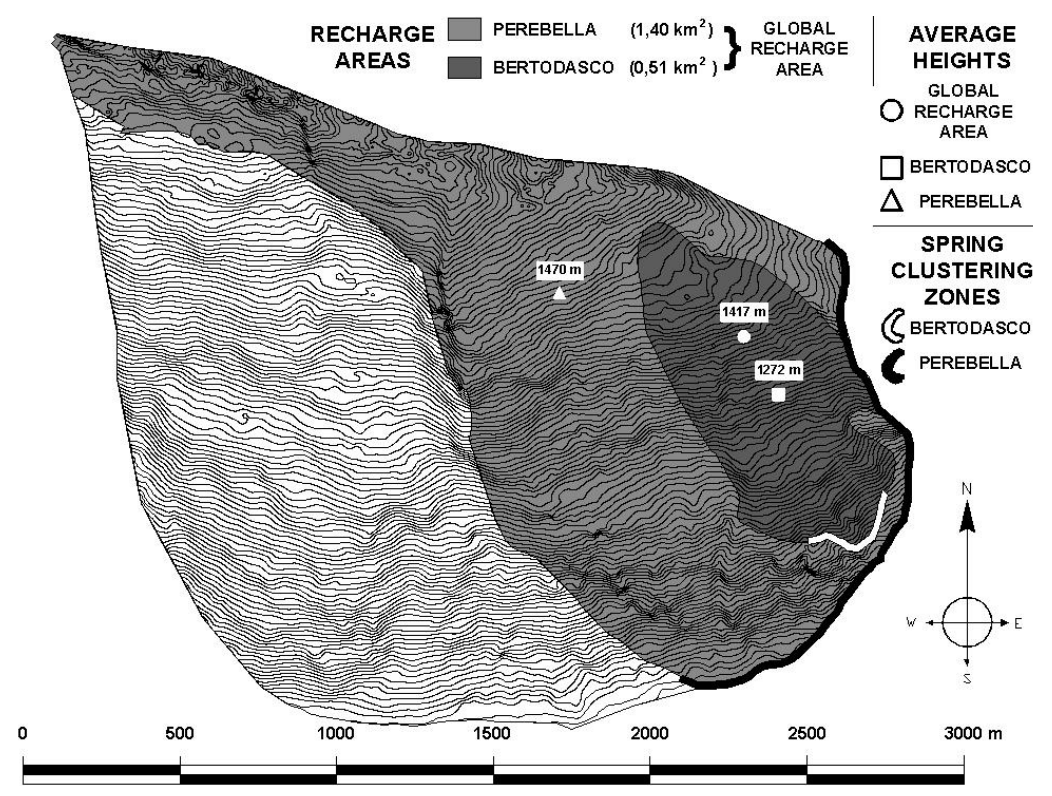

Fig. 5. The Perebella (light grey) and Bertodasco (dark grey) recharge areas, with evidence of the average heights of the slope under consideration and of the spring clustering zones.

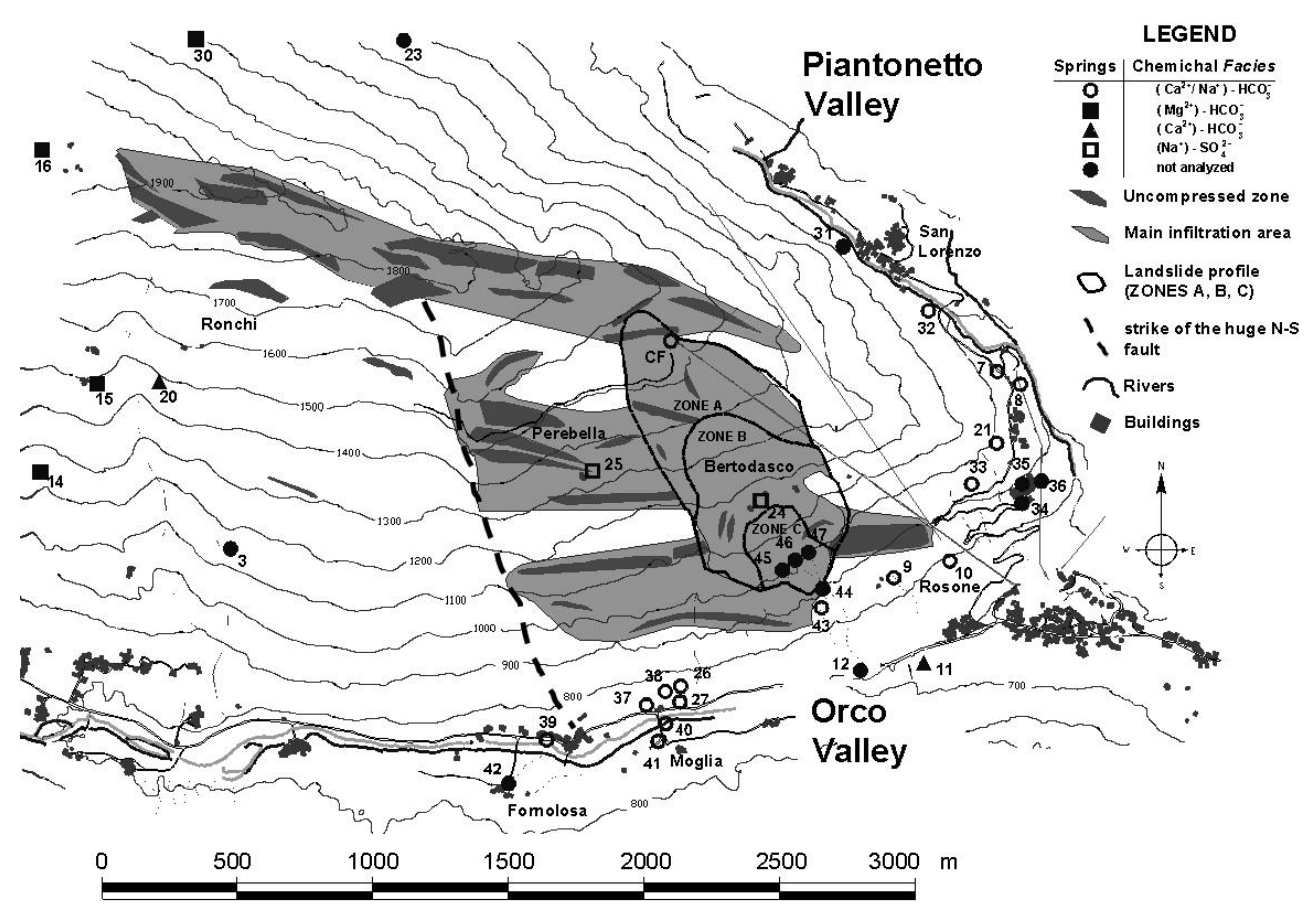

Fig. 6. Water chemistry of the Rosone landslide with indication of the global recharge area, of the landslide profile and of the N-S fault which separates the Perebella sector from the Ronchi sector (modified from Binet et al., 2007).

Under the assumption of a normal hydraulic regime (i.e., the number of wet periods equals the number of dry periods), the satisfactory water budgets evaluated in the Bertodasco and Perebella areas (unbalances of $6 \%$ and $1 \%$, respectively, as shown in Table 1) have allowed us to preliminary confirm the hypothesis of independent aquifers.
The results of the chemical analyses, shown in Figs. 6 and 7, seem to confirm, at a local level, the Sacchi et al. (2004) hypotheses concerning the different groundwater flow systems at a valley scale. 
Table 1. Water budget of the Rosone slope for the year 2008.

\begin{tabular}{|c|c|c|c|c|c|c|c|c|}
\hline & \multirow{2}{*}{$\begin{array}{l}\text { Rainfall } \\
\text { mm }\end{array}$} & \multicolumn{2}{|c|}{ Snowfall $^{* *}$} & \multirow{2}{*}{$\begin{array}{c}\text { Temper. } \\
{ }^{\circ} \mathrm{C}\end{array}$} & \multirow{2}{*}{$\begin{array}{c}\text { Evapotr. } \\
\text { mm }\end{array}$} & \multirow{2}{*}{$\begin{array}{c}Q_{\text {in }} \\
\mathrm{m}^{3} \mathrm{~h}^{-1}\end{array}$} & \multirow{2}{*}{$\begin{array}{c}Q_{\text {out }} \\
\mathrm{m}^{3} \mathrm{~h}^{-1}\end{array}$} & \multirow{2}{*}{$\begin{array}{c}\text { Balance* } \\
-\end{array}$} \\
\hline & & $\mathrm{cm}$ & $\mathrm{mm}_{\mathrm{SWE}}$ & & & & & \\
\hline Bertodasco sector (2 springs) & 1626 & 374 & 449 & 7.3 & 474 & 93 & 99 & $-6 \%$ \\
\hline Perebella sector (14 springs) & 1579 & 454 & 544 & 6.3 & 449 & 267 & 270 & $-1 \%$ \\
\hline Global recharge area & 1591 & 432 & 519 & 6.6 & 456 & 361 & 369 & $-2 \%$ \\
\hline
\end{tabular}

* water budget calculated as: $\left(Q_{\text {in }}-Q_{\text {out }}\right) /\left[\left(Q_{\text {in }}+Q_{\text {out }}\right)\right]$;

** Snow Water Equivalent (SWE) calculated as: $\mathrm{mm}_{\text {water }}=\mathrm{mm}_{\text {snow }} \rho_{\text {snow }} / \rho_{\text {water }}$ where $\rho_{\text {snow }}$ and $\rho_{\text {water }}$ are the snow and water densities, respectively.

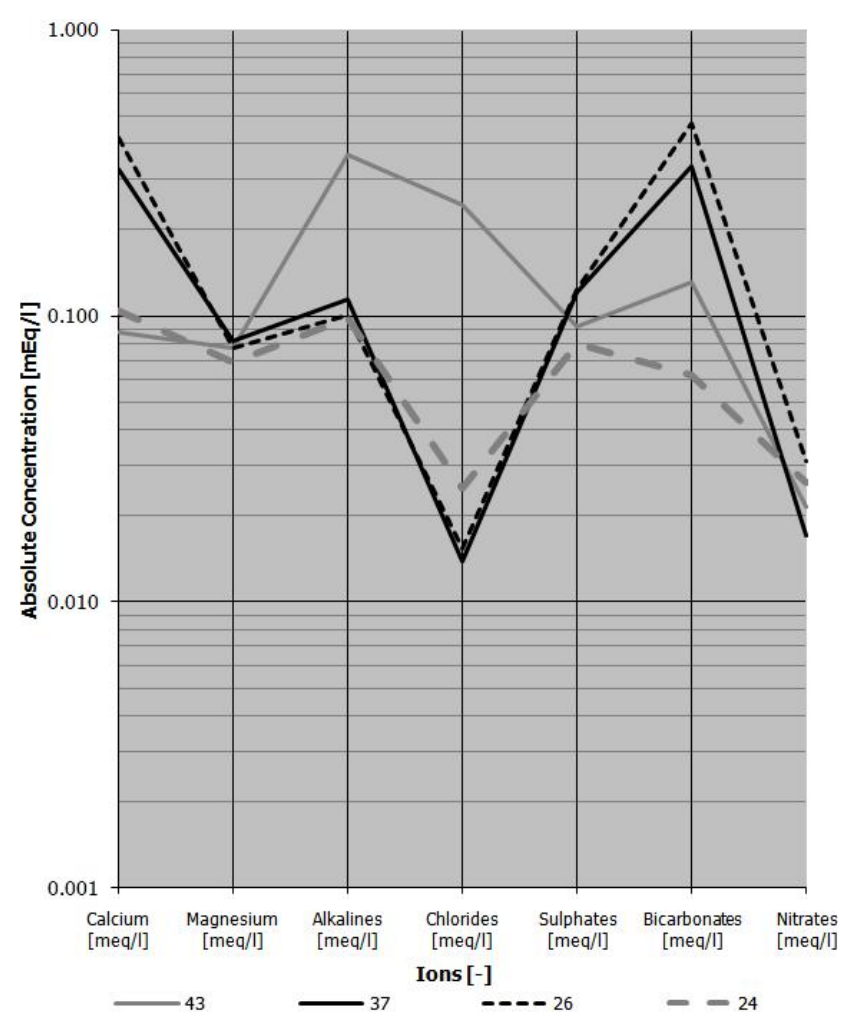

Fig. 7. Schöeller's diagram of major ions concentration (April 2009 investigation campaign): evidence of the different chemistry of springs 26, 37 and 43 (calcium-alkaline bicarbonate water, deep groundwater flow system) and of spring 24 (calcium-magnesium sulphate water, rapid groundwater flow system).

Two different kinds of water circulation can therefore be hypothesised inside the slope: a very shallow, perched one characterised by water with a slight dominance of calciummagnesium sulphate ion concentrations in the springs located in Bertodasco and Perebella (springs 24 and 25 in Figs. 6 and 7) and a deeper, more important one, with calciumalkaline bicarbonate water in the many springs located at the toe of the landslide and at the toe of the slope (e.g., springs 26, 32, 33, 37 and 43 in Figs. 6 and 7).
Since the water from springs 24 and 25 (see Fig. 6) directly re-infiltrates within the landslide body a few meters after the outflows and it is then apparent that the perched aquifer is entirely within the shallow aquifer, it was therefore not accounted for within the model (see Fig. 11).

\section{Investigation and monitoring}

Systematic investigations and geomechanical studies have been conducted on the entire rock mass involved in the sliding activities since 1985, with special attention to the Bertodasco sector (Forlati et al., 1991; Regione Piemonte and Université J. Fourier, 1996).

The studies that have been carried out can be summarised as:

1. surface investigations to characterise the rock mass and the main discontinuity system;

2. geophysical investigations (seismic profiles);

3. in-depth investigations with reference to boreholes drilled with continuous coring to a depth of $120 \mathrm{~m}$, subsequently equipped with piezometers and inclinometers to measure pore pressure and deep seated displacements;

4. laboratory tests to geomechanically characterise the cores, examining both the discontinuity surfaces (schistosity) and the intact cored material.

Moreover, an integrated monitoring system with automatic data recording was installed in 2000 to monitor the displacements around the Bertodasco sector.

\subsection{Surface investigations}

The structural characterization of the rock mass, carried out in the central sector of Perebella, shows three main discontinuity systems (Fig. 8):

- schistosity $S_{\mathrm{R}}$, with a mean dip direction of $154^{\circ}$ and a dip of $34^{\circ}$;

- a sub-vertical joint system $\mathrm{K}_{1}$, with a mean dip direction of $280^{\circ}$ and a dip of $86^{\circ}$; 

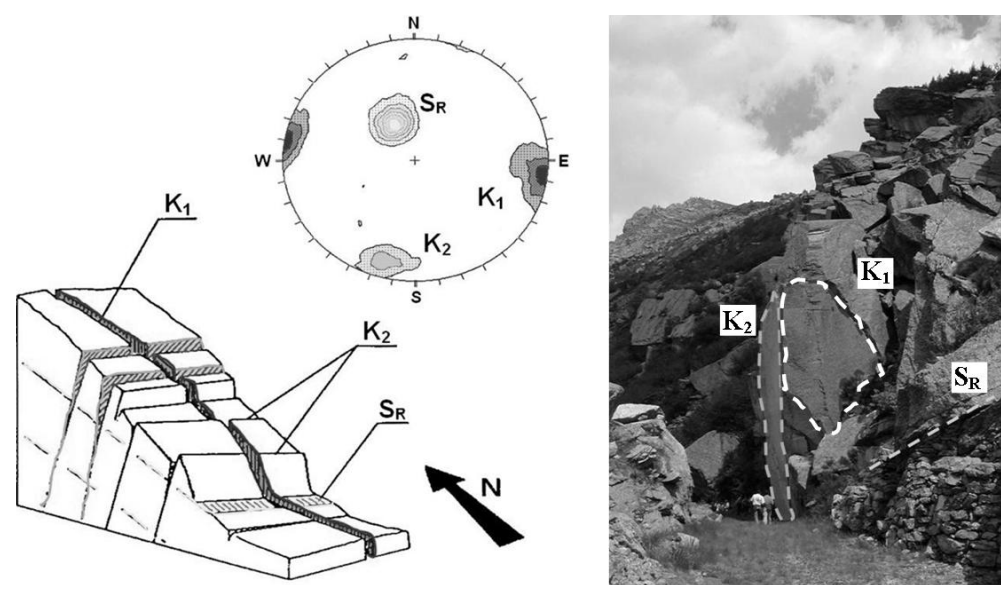

Fig. 8. 3-D sketch of the main tectonic discontinuities of the Rosone area, Schmidt diagram (lower hemispheric) showing pole concentrations and field evidence of joint sets.

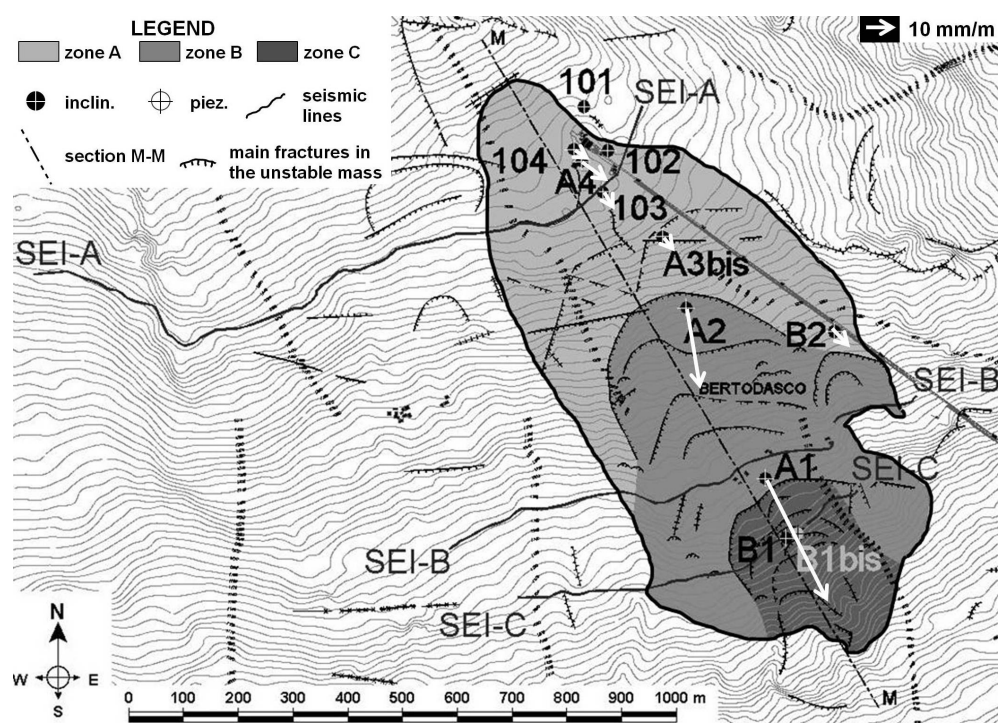

Fig. 9. Morpho-structural map of the Bertodasco sector, showing the subdivision into distinct morphological areas A, B and C (see section M$\mathrm{M}$ in Fig. 11), the main fractures, the position of the inclinometers, piezometers and seismic lines (SEI-A, SEI-B, SEI-C) and the displacement vectors from automatic inclinometric measurements between 1 August 2001 and 31 July 2006 (Careggio, 2006).

- a sub-vertical joint system $\mathrm{K}_{2}$, with a mean dip direction of $10^{\circ}$ and a dip of $68^{\circ}$.

The two main orthogonal fracture systems $\left(\mathrm{K}_{1}\right.$ and $\left.\mathrm{K}_{2}\right)$ in the Perebella sector display wide-open fractures and, in some cases, simply juxtaposed rock elements. However, the three discontinuity systems are also locally evident in the Bertodasco sector, even though it is much more chaotic and disrupted.

A comparison with the observations at the massif scale (see Figs. 3 and 8) has allowed us to identify a correlation between system $\mathrm{K}_{1}$ and schistosity $S_{\mathrm{R}}$ and the N-S major fault and the persistent and highly-spaced shear zones, respectively.

\section{Geophysical investigations}

Some seismic reflection profiles and a down-hole log were performed along three lines, SEI-A, SEI-B and SEI-C roughly perpendicular to the maximum dip line of the slope (see Figs. 9 and 10), supplying data on the physical properties of the rock mass and the landslide body thickness. The results, in terms of wave propagation velocity, underline different layers with different behaviour (Bonnard et al., 2004). The superficial layer is characterised by a low wave velocity, which can be associated to a loose rock mass, whereas the deepest layer has revealed a higher wave velocity (around $2000 \mathrm{~m} \mathrm{~s}^{-1}$ ), which could be linked to a structured rock body. 


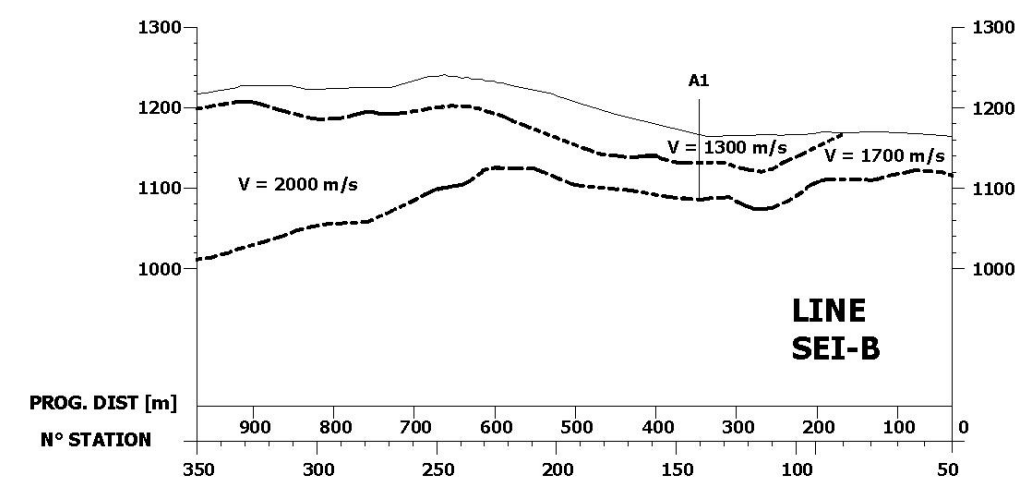

Fig. 10. Seismic reflection profiling performed along line SEI-B (Bertodasco sector), see Fig. 9 for the position of the profile.

Table 2. Summary of the inclinometric measurements.

\begin{tabular}{|c|c|c|c|c|c|c|}
\hline & \multicolumn{2}{|c|}{ Measurement period } & \multirow{2}{*}{$\begin{array}{c}\text { Depth* } \\
\text { m }\end{array}$} & \multirow{2}{*}{$\begin{array}{l}\text { Displacement } \\
\text { mm }\end{array}$} & \multirow{2}{*}{$\begin{array}{l}\text { Velocity } \\
\mathrm{mm} \mathrm{y}^{-1}\end{array}$} & \multirow{2}{*}{$\begin{array}{c}\text { Azimuth }^{* *} \\
\circ\end{array}$} \\
\hline & Initial & Last & & & & \\
\hline A1 & Dec 1991 & Jun 1999 & 38.37 & 157.1 & 21.0 & 188 \\
\hline A2 & Dec 1991 & Oct 2008 & 45.00 & 216.8 & 14.7 & 156 \\
\hline A3 & Dec 1991 & Oct 1993 & 70.49 & closed & closed & closed \\
\hline A3bis*** & Nov 1999 & Oct 2008 & 70.99 & 70.0 & 3.7 & 133 \\
\hline A4 & Dec 1991 & Oct 2008 & 29.50 & 70.8 & 6.7 & 210 \\
\hline 101 & Dec 1984 & Nov 1993 & 3.05 & 57.7 & 6.4 & 149 \\
\hline 102 & Dec 1984 & Oct 2008 & 22.49 & 93.1 & 6.5 & 180 \\
\hline 103 & Dec 1984 & Oct 2008 & 53.50 & 159.8 & 7.3 & 175 \\
\hline 104 & Dec 1984 & Nov 2000 & 20.12 & 89.5 & 5.6 & 150 \\
\hline B1 & Nov 1999 & Oct 2000 & 39.62 & 134.5 & closed & 145 \\
\hline B2 & Nov 1999 & Oct 2008 & 37.49 & 74.9 & 18.9 & 161 \\
\hline
\end{tabular}

* Depth of maximum inclinometric deformation. ${ }^{* *}$ Azimuth measured clockwise from the North. ${ }^{* * *}$ Redrilled.

An intermediate layer is found below seismic reflection lines SEI-B (Fig. 10) and SEI-C. These results have allowed us to preliminary confirm the hypothesis made on the basis of geomorphological considerations, in particular concerning the presence of two different interfaces in the rock mass, which can be associated to the shear bands observed at a slope scale.

\section{In depth investigations}

A number of boreholes were drilled inside the rock mass in different periods from 1984 to 1999, supplying detailed stratigraphic information.

An exhaustive analysis of the stratigraphic plots, which reach a depth of about 100-120 m, confirms the presence of two weak layers that can be associated to the shear bands observed at a slope scale. Some of the plots show only one of the bands, probably because the borehole was not sufficiently deep.

Ten boreholes were then equipped for manual inclinometric readings and the results of these measurements are summarised in Table 2.
The measurements clearly show that movements take place on the shallow shear band (failure zone), at a depth that varies from $3 \mathrm{~m}$, in the upper part, to around $70 \mathrm{~m}$ in the central part of the landslide body.

Two piezometers were also installed at two different depths $(29 \mathrm{~m}$ and $41 \mathrm{~m}$ ) in borehole Albis (a redrilled borehole close to A1) and the water pressure was recorded from 1992 to 1996. Interpretation of these data is not straightforward, due to the complex hydrogeological conditions of the slope and the lack of other continuous pore water pressure data at that time. However, the results seem to indicate the presence of two different groundwater systems, located above and below the shallow shear failure zone, respectively. Unfortunately, these instruments stopped working in 1996 and another automatic piezometer was installed in 2000 in borehole B1bis (close to B1), at a depth of $36 \mathrm{~m}$ (i.e. just above the failure zone, see Figs. 11 and 12).

On the basis of these results, of the morphological and structural data and of the observations described in the previous sections, the cross section in Fig. 11, which shows the presence of the two shear bands (the deeper of which is 


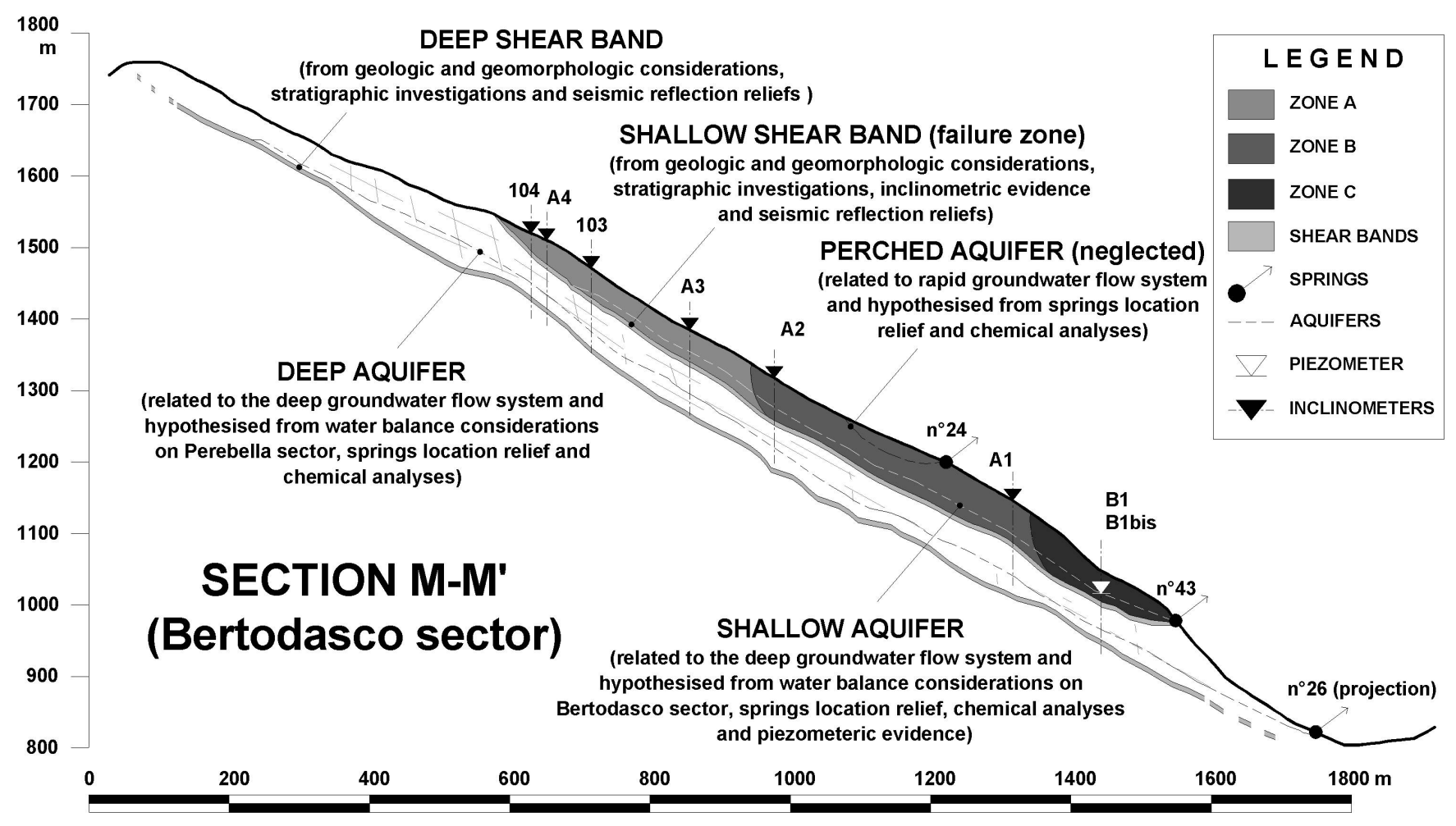

Fig. 11. Cross section of the Rosone landslide (section M-M in Fig. 9) with the position of the inclinometers and the piezometer. The shape and position of the failure zone have been derived from inclinometric measurements and the positions of the aquifers have been hypothesised by field evidence and chemical analyses. The position of the springs is also indicated.

located approximately $50 \mathrm{~m}$ below the shallower) has been obtained. The figure also shows the position of the instruments, the zone classification and the hypothesised location of the aquifers.

Figure 12 shows a more detailed view of the results of the investigation campaigns on the lower part of the landslide.

From a comparison of the stratigraphic log data and the drilled material from boreholes $\mathrm{A} 1$ and $\mathrm{B} 1$, the following conclusions can be drawn:

- the first 35/40 m of cored rock material are characterised by heterogeneously sized gneissic blocks, with many voids and fillings of different materials (panel 1 in Fig. 12);

- the first shear band is intercepted at approximately $40 \mathrm{~m}$ from the ground level (even though its depth varies along the section), and its thickness varies from 2 to $7 \mathrm{~m}$. The deformational process here seems to be at an advanced stage of evolution, and the rock material has lost its mechanical properties and has assumed the characteristics of a breccia (slightly clayey sandy silt with gravel and with traces of finer material which has mostly been washed away, see panel 2 in Fig. 12). The evolution of this shallower shear band could be due to the movement of the landslide which preferentially developed there, as confirmed by the inclinometric deformation;

- a 40/50 m thick zone of massive granitic gneiss with some fractures is found below the shallower shear band. The core drilled from borehole A1 clearly shows the presence of undeformed but fractured rock material at that depth. This can be seen from an observation of Figs. 12 (panels 3 and 5a), where the typical eye-shaped mineral grains in the mylonitic augen gneissic rock matrix are large, which is a sign of the undeformed condition of the rock;

- a new shear band is detected at a depth of 90/100 m, where the eye-shaped mineral grains are squashed and elongated along the main movement direction (see panels 4 and $5 \mathrm{~b}$ in Fig. 12, respectively). This is a sign that shear deformation has occurred in the augen gneissic rock matrix.

\section{Laboratory tests}

Laboratory tests were carried out at the beginning of the 1990s to geomechanically characterise the core samples, including both the discontinuity surfaces (schistosity) and 

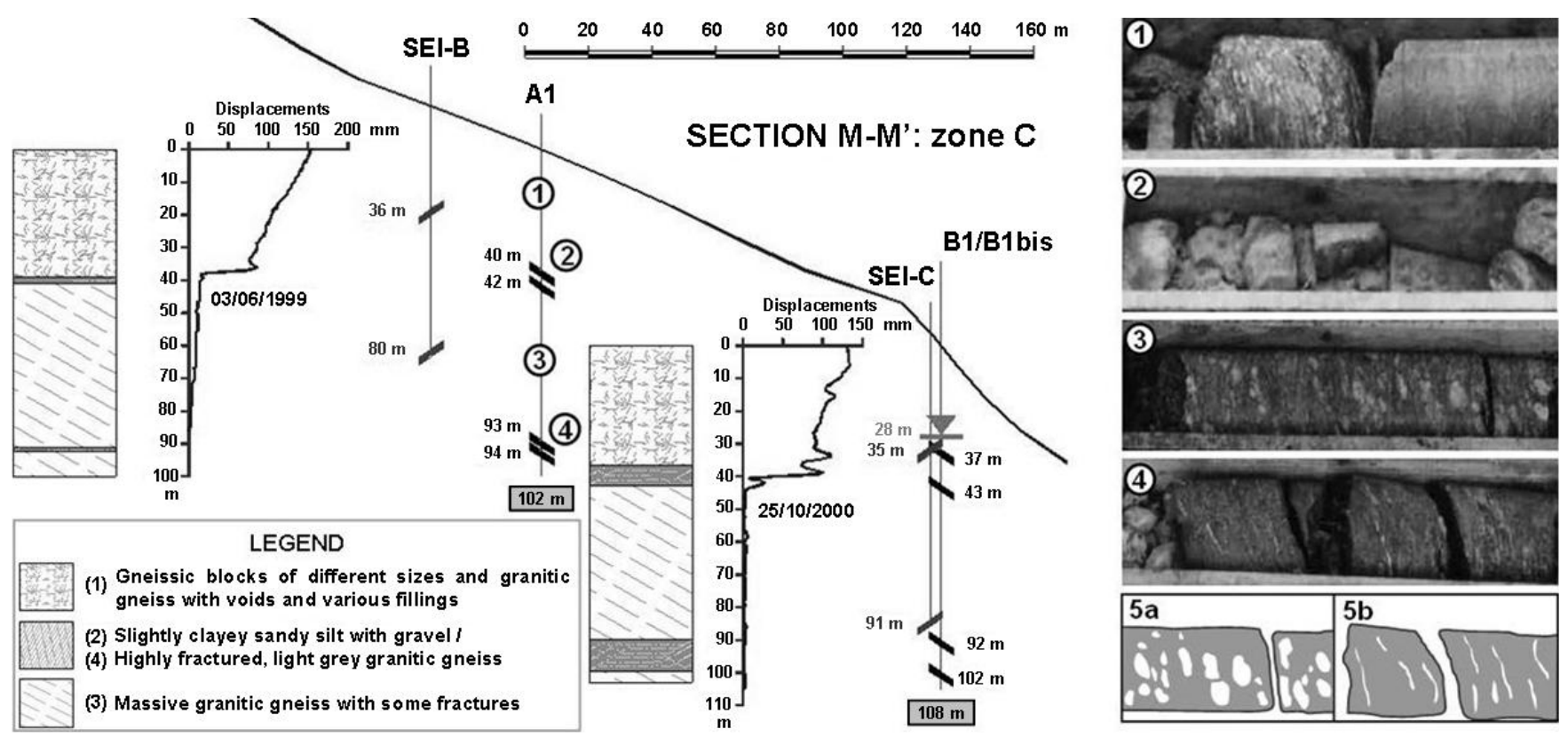

Fig. 12. Simplified stratigraphic plots in the lower part of the landslide body (zone C), with indication of the inclinometric measurements in boreholes A1 and B1, the water table level in borehole B1bis and the different layer depths from seismic profile SEI-B (36 m and $80 \mathrm{~m})$ and SEI-C (28 m and $91 \mathrm{~m})$. Pictures of the cores drilled from borehole A1 are also shown (1-4) and a sketch of the different stages of evolution of the augen gneiss highlighted in (3) and (4) is shown in (5a) and (5b), respectively.

the rock matrix. These tests provided the following average values of the relevant mechanical parameters (Regione Piemonte and Université J. Fourier, 1996): unit weight of $26.5 \mathrm{kN} \mathrm{m}^{-3}$ and uni-axial compression strength $C_{0}$ of $110 \mathrm{MPa}$ for the rock material; base friction angle of $34^{\circ}$, Joint Roughness Coefficient JRC of 11 and Joint Compressive Strength JCS of $75 \mathrm{MPa}$ for the schistosity.

Some samples of disturbed soil were also tested. These tests were taken from the disrupted and weathered landslide body and the shallower shear band. Granulometric grain size distribution tests, Atterberg limits and a USCS classification were carried out. Samples from the shear band showed similar characteristics, even though variability in the granulometric fractions has been encountered. The liquid limit results to be around 22-26\%, the plastic limit about $16 \%$ and the plasticity index around $5.5-10 \%$. On the basis of the USCS classification, the breccia material can be classified as silty sand with variable clay fractions and the presence of gravel.

\section{Automatic monitoring system}

After many years of studies of the landslide area, an integrated system with automatic data recording was installed in December 2000. The main components of the system include:

- a topographic network to measure superficial displacements;
- a geomechanical network to measure superficial and deep deformations and water pressure inside the rock mass;

- a hydro-meteorological network to measure temperature, humidity, rain and snow.

The recorded monitoring system data have been analysed in detail by Careggio (2006) in order to draw some conclusions on the velocities of the landslide, the displacement vectors and their directions.

In particular, concerning the geomechanical and the hydro-meteorological networks, the analysed instruments (inclinometers, crackmeters, extensometers in boreholes, wire extensometers, piezometers and pluviometer) have globally shown quite reliable measurements, except for occasional periods in which the lack of data is mainly due to the malfunctioning of the data transmission junction box. Inclinometer B1, located in sector C stopped recording after a short period (less than 1 year) because of large displacements due to landslide movements.

The analysis of the data shows different displacement intensities and velocities in the different zones of the landslide, identified from geomorphological studies and from photo interpretations, i.e. zones A, B and C. In particular, the highest displacements have been registered in zones $\mathrm{B}$ and $\mathrm{C}\left(40 \mathrm{~mm} \mathrm{~m}^{-1}\right.$ for inclinometer $\mathrm{A} 1$ and $20 \mathrm{~mm} \mathrm{~m}^{-1}$ for inclinometer A2 in the 2001-2006 period), and the lowest displacements have been registered at the top of the 


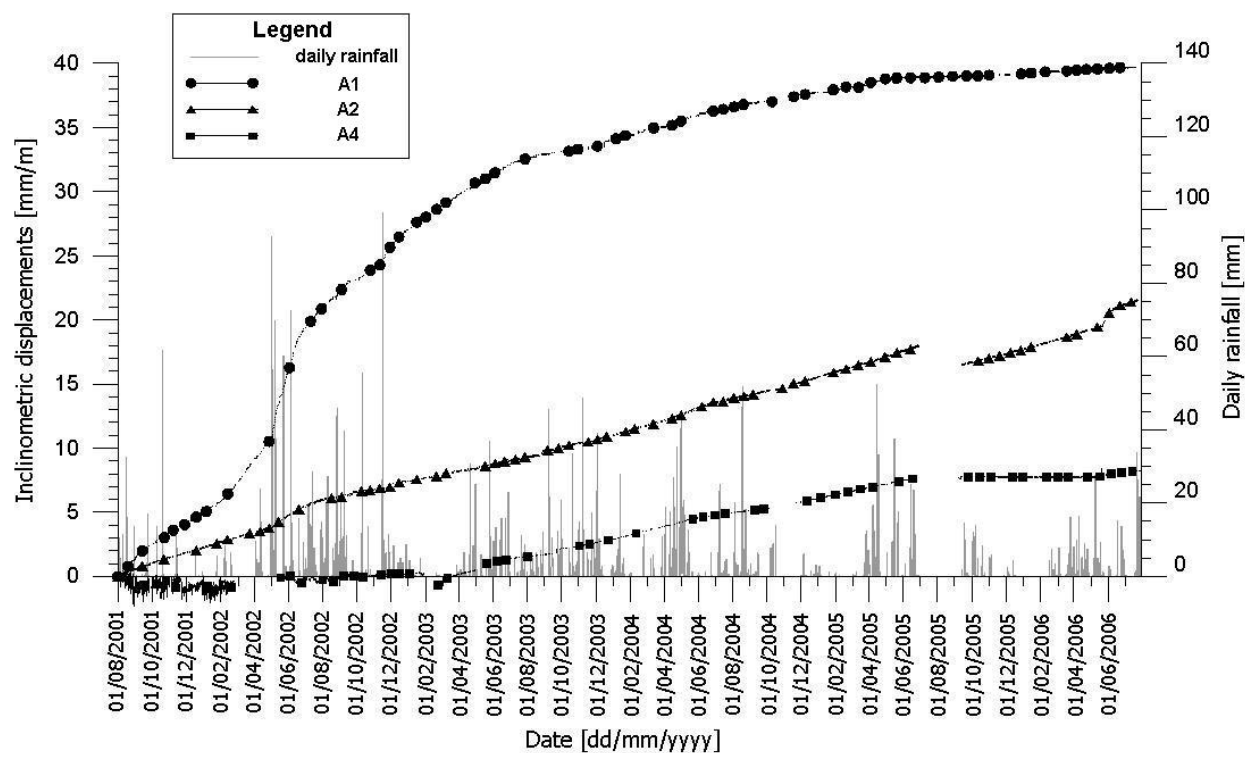

Fig. 13. Automatic inclinometric measurements (boreholes A1, A2, and A4) versus time between 1 August 2001 and 31 July 2006 , compared to the daily rainfall registered in the Bertodasco sector.

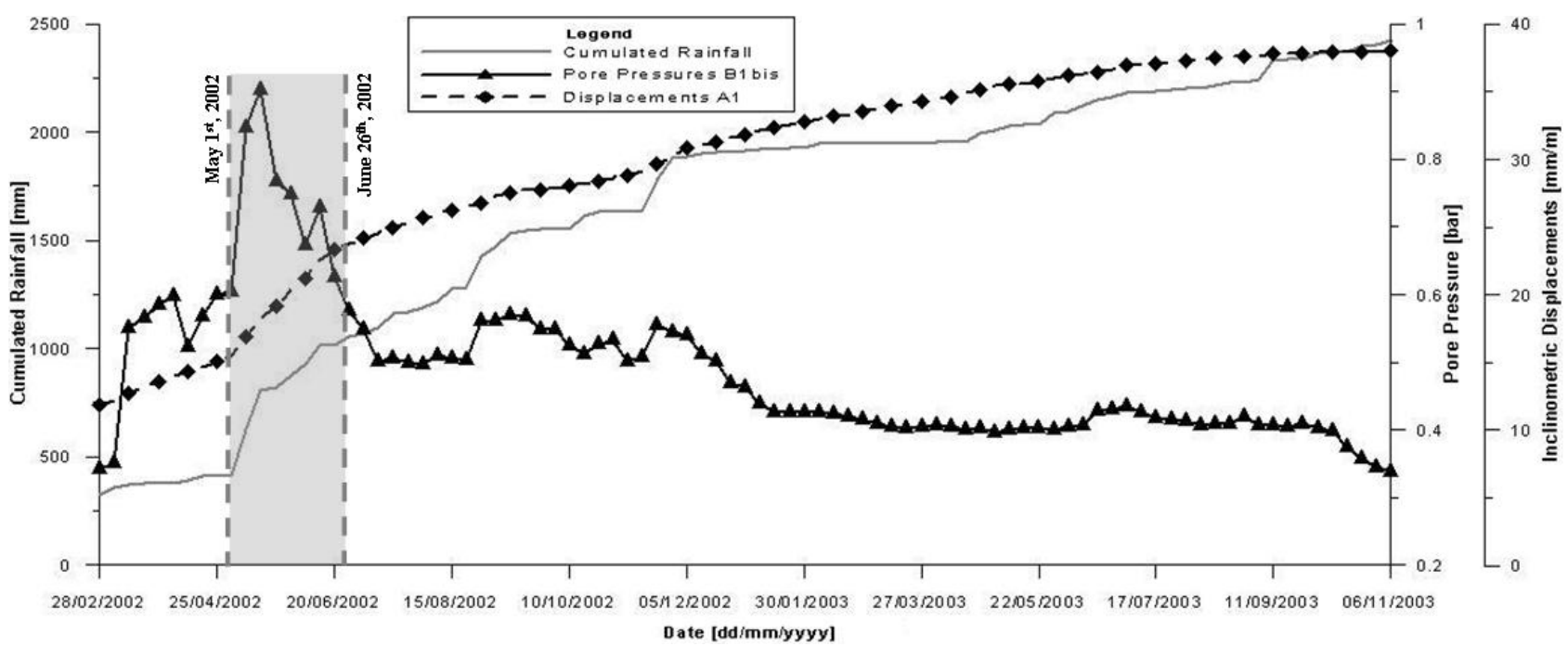

Fig. 14. Automatic piezometric (borehole B1bis) and inclinometric (borehole A1) measurements versus time over a period of intense rainfall (March 2002-November 2003) compared to the cumulative rainfall recorded in the Bertodasco sector and indication of the reference period adopted for the numerical analyses (1 May-26 June 2002).

landslide (zone A), near the AEM-IRIDE pools $\left(10 \mathrm{~mm} \mathrm{~m}^{-1}\right.$ at inclinometer A4 for the same period, see Fig. 13). This difference has also been confirmed from an analysis of superficial instruments: the crackmeters in the pools and the wire extensometers in the principal fractures in the Bertodasco sector.

The displacement direction highlighted by inclinometers seems to be quite uniform in time and quite similar to that observed during previous manual recordings, and it is consistent with the orientation of the failure zone (Fig. 9).
All the analysed instruments show a good correlation with the precipitation trend. Sharp pore pressure increments and significant variations in the displacement velocities have been recorded a few days after heavy rainfall.

Some of the local accelerations in the displacements can therefore be correlated to the recorded amount of rainfall and the consequent increase in the pore pressure, as can be observed in Fig. 14 with reference to inclinometer A1 and piezometer B1bis, which are located in the lower zones of the Bertodasco sector (zones B and C). 
Table 3. Summary of main previous periods of data collection with evidence of original contributions.

\begin{tabular}{|c|c|c|}
\hline Reference & Date & Data collected/observation made \\
\hline Ramasco et al. & 1989 & $\begin{array}{l}\text { geological and geomorphological observation, drilled cores interpretation, } \\
\text { historical researches; }\end{array}$ \\
\hline Forlati et al. & 1991 & surface and in-depth investigation, laboratory tests; \\
\hline $\begin{array}{l}\text { Regione Piemonte and Universitè J. Fourier } \\
\text { (Eds. - VV.AA.) }\end{array}$ & 1996 & $\begin{array}{l}\text { collection and interpretation of measured displacements } \\
\text { (periods 1953-1971, 1981-1993); }\end{array}$ \\
\hline Bonnard et al. (Eds. - VV.AA.) & 2004 & $\begin{array}{l}\text { collection and interpretation of measured displacements and pore pressure } \\
\text { (period 1993-1999), interpretation of seismic reflection reliefs (2000); }\end{array}$ \\
\hline Careggio & 2006 & $\begin{array}{l}\text { pore pressure, surface and in-depth displacements continuous collection } \\
\text { (period 2001-2006) and interpretation; }\end{array}$ \\
\hline Binet & 2007 & census of the springs, chemical analyses; \\
\hline Present study & 2009 & $\begin{array}{l}\text { geomorphological considerations (update), census of the springs (update), } \\
\text { chemical analyses (update), monitoring of some springs (period 2008-2009), } \\
\text { collection and interpretation of measured pore pressure, surface and } \\
\text { in-depth displacements (period 2006-2009). }\end{array}$ \\
\hline
\end{tabular}

This correlation seems to suggest a very slow gravitational movement with local accelerations driven by the increasing pore pressure due to water infiltration inside the disrupted and weathered landslide body, which is characterised by a deep groundwater circulation.

This hypothesis could be confirmed through an accurate hydro-mechanical numerical analysis of the landslide behaviour, able to simulate both the transient state of water infiltration and circulation inside the slope and the correlated mechanical behaviour of the shear zone and the disrupted mass located above.

However, this kind of analysis requires not only the modelling of the mechanical properties of the disrupted material and the shear failure zone, but also an accurate hydrogeological model of the massif, in order to reproduce the saturation of the aquifer due to water infiltration and the consequent increase in water pressure locally observed by the piezometer.

The geomorphological observations and the analysis of the springs and of the water chemistry could drive the definition of a simplified hydrogeological model based on the hypothesis of two different flow systems. Neglecting the very shallow perched aquifer (springs 24 and 25) for the reasons described in Sect. 3, two different aquifers belonging to the deep groundwater flow system can be hypothesised on the basis of the results of the chemical analyses. The in depth investigations (see Sect. 4.3) has allowed us to assume that these aquifers are constrained by the two differently evolved shear bands (see Figs. 11 and 12), whose high deformation levels induced hydraulic properties of very low permeability. The hypothesis of independence of these two deep aquifers can then be done. Moreover, the deeper shear band (less evolved than the upper one and only intercepted by boreholes B1 and A1 because of its depth) seems to act as a constraint to water circulation in the deeper aquifer rather than playing an active role in the mechanical instability process: hence, the numerical hydraulic analyses have been performed on a simplified model of the slope, as described in the following section.

Finally, a summary of previous studies and of periods of data collection and interpretation described in Sects. 3 and 4 is presented in Table 3 with evidence of original contributions to the data acquisition and to the development of a conceptual hydrogeological model.

\section{Numerical analyses}

A set of numerical analyses was carried out with the aim of simulating the pore pressure fluctuations recorded by the automatic piezometer B1bis (see Fig. 14) during a period of intense rainfall.

The huge dimensions of this large and deep landslide in heterogeneous rock make simplifications unavoidable:

- since the discontinuity systems (see Fig. 8) are only recognizable in small portions of the slope, the high degree of disruption of the rock mass suggested the adoption of a continuum equivalent model, assuming hydraulic parameters which need to be scaled down with respect to those of the rock material;

- due to the fact that the landslide preferentially imposed on the shallower and more evolved shear band and that the rock located below does not show any evidence of high deformation (see Fig. 12), both the deeper aquifer and the deeper shear band were neglected in the model; 


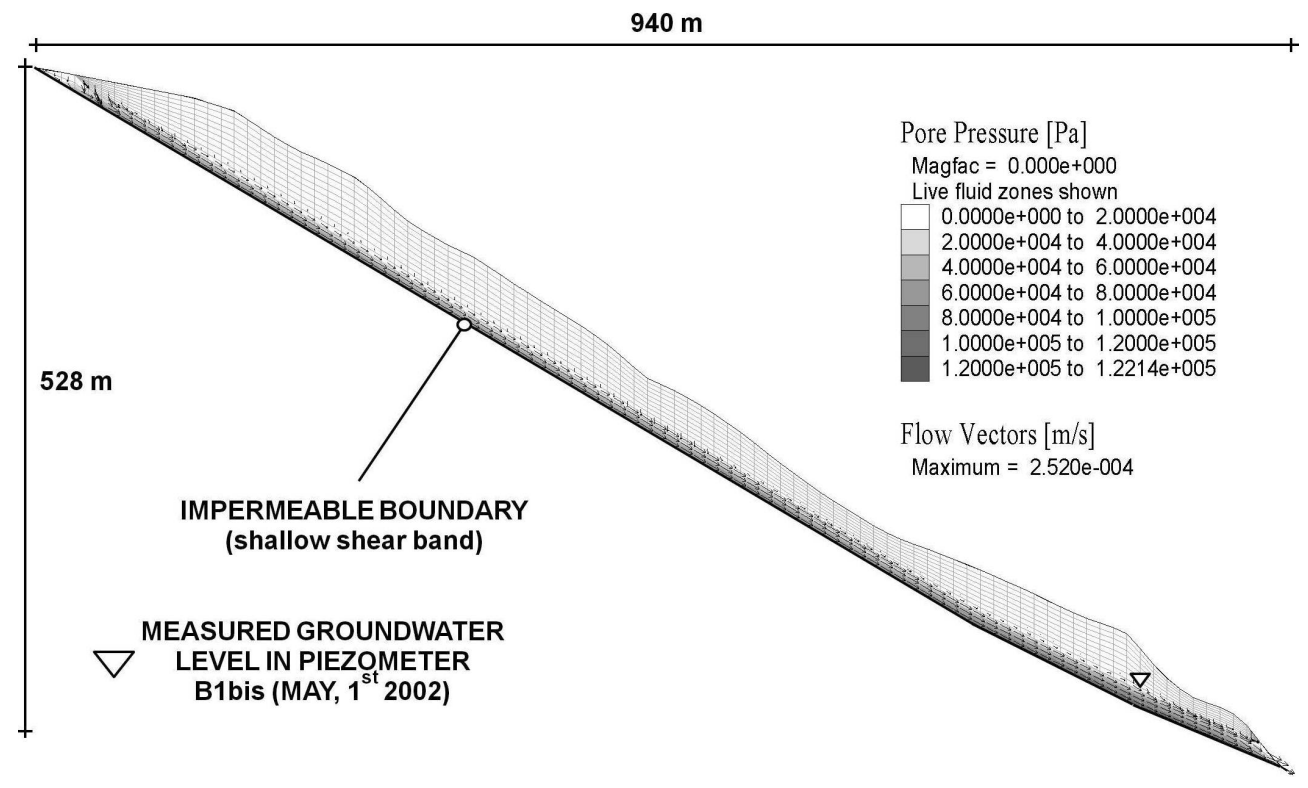

Fig. 15. Two-dimensional FLAC ${ }^{3 \mathrm{D}}$ mesh of the Rosone landslide with evidence of (a) boundary conditions, (b) computed pore pressure distribution, (c) computed flow lines and (d) measured groundwater level (piezometer B1bis, 1 May 2002).

- the displacements seem to be concentrated within the shallow shear band (failure zone), which could be represented, as a first approximation, as a shear surface close to the residual conditions (see inclinometric deformations in Fig. 12);

- due to the lack of information about the threedimensional pore pressure distribution within the rock mass and to the fact that the water of the shallower aquifer seems to preferentially flow along the main axis of the landslide, a simplified two-dimensional numerical mesh in plain strain conditions was adopted (see section M-M in Figs. 11 and 15);

- the minimum measured groundwater level (initial steady-state condition for transient hydraulic flow analyses) was assured by an internal flow (i.e., the initial pore pressure distribution derives from a numerical hydraulic steady-state flow analysis in which the water flows within the saturated portion of the disrupted rock mass);

- all the rainfall was effective (i.e., all the water infiltrated);

- due to the large voids of the rock mass, the hypothesis of negative pore pressure above the phreatic surface was considered as unrealistic (i.e., the disrupted rock mass is assumed as a very coarse gravel, see Fig. 12 panel 1).

With the purpose of performing three-dimensional hydromechanical analyses at a later date, the numerical purely hydraulic simulations (i.e., the numerical mechanical component is switched off) were performed with the $\mathrm{FLAC}^{3 \mathrm{D}}$ finite difference code, which allows the unsaturated flow through a porous medium. The variables involved in the description of fluid flow through a porous media are the pore pressure, the degree of saturation and the three components of the specific discharge vector. These variables are related through the Darcy law for fluid transport, an equation of state relating pore pressure to saturation in the unsaturated range, the fluid mass-balance equation and a constitutive equation specifying the fluid response to changes in pore pressure and saturation.

Substitution of the mass balance equation into the fluid constitutive relation, using Darcy law, yields a differential equation in terms of pore pressure and saturation that may be solved for particular geometries, properties, boundary and initial conditions. The fluid transport is obviously described by Darcy law. For a homogeneous, isotropic solid and constant fluid density, this law is given, in indicial notation, in the form:

$q_{i}=-k_{i l} \hat{k}(S)\left[p-\rho x_{j} g_{j}\right]_{i l}$

where $\hat{k}(S)$ is the relative mobility coefficient (which is a function of fluid saturation $S$ ), $k_{i l}$ is the tensor of absolute mobility coefficients (FLAC ${ }^{3 \mathrm{D}}$ permeability tensor) of the medium, $q_{i}$ is the specific discharge vector, $\rho$ is the fluid density, $p$ is pore pressure and $g_{i}, i=1,3$ are the three components of the gravity vector. For saturated/unsaturated flow in $\mathrm{FLAC}^{3 \mathrm{D}}$, the air pressure is assumed to be constant and equal to zero. Since the influence of capillary pressure is neglected (the fluid pressure is equal to air pressure when saturation is less than one, and air pressure is zero in the unsaturated zone) in the $\mathrm{FLAC}^{3 \mathrm{D}}$ formulation, the relative 
Table 4. Geometrical characteristics of the mesh and unit weight of both the rock mass and the fluid used in the two-dimensional finite difference analysis.

\begin{tabular}{lcc}
\hline Parameter & Value & $\begin{array}{c}\text { Unit of } \\
\text { measurement }\end{array}$ \\
\hline Horizontal extension & 940 & $\mathrm{~m}$ \\
Vertical extension & 528 & $\mathrm{~m}$ \\
Mesh size in the horizontal direction & 10 & $\mathrm{~m}$ \\
Number of cells in the vertical direction & 12 & - \\
Total number of cells & 1078 & - \\
Saturated unit weight of the rock mass & 26.5 & $\mathrm{kN} \mathrm{m}^{-3}$ \\
Unit weight of the water & 9.8 & $\mathrm{kN} \mathrm{m}^{-3}$ \\
\hline
\end{tabular}

fluid mobility is related to saturation by the following cubic law:

$\hat{k}(S)=S^{2}(3-2 S)$

which has the property that $\hat{k}(0)=0$ if $S=0$ and $\hat{k}(1)=1$ if $S=1$.

It is clear that fluid flow in the unsaturated zone is thus solely driven by gravity; moreover, while the influence of gravity is not required to saturate an initially dry medium, gravity drives the process of desaturation.

In the $\mathrm{FLAC}^{3 \mathrm{D}}$ formulation, the fluid mass balance is expressed by:

$-q_{i, i}+q_{\mathrm{V}}=\frac{\partial \vartheta}{\partial t}$

where $q_{\mathrm{V}}$ is the volumetric fluid source intensity, $\vartheta(=n S)$ is the variation of fluid content or variation of fluid volume per unit volume of porous material due to diffusive fluid mass transport as introduced by Biot (1956), and $n$ is the porosity.

From a constitutive point of view, changes in variation of fluid content are related to changes in pore pressure and saturation, and the response equation for the pore fluid is formulated as:

$\frac{n}{K_{\mathrm{f}}} \frac{\partial p}{\partial t}+\frac{n}{S} \frac{\partial S}{\partial t}=\frac{\partial \vartheta}{\partial t}$

where $K_{\mathrm{f}}$ is the fluid bulk modulus.

Geometrical features of the mesh and unit weight of the rock mass are summarised in Table 4.

First, a steady-state hydraulic analysis has been developed to initialise both a consistent pore pressure distribution and a suitable groundwater flow regime within the porous rock mass through the simulation of the piezometric level as it was recorded by piezometer B1bis at the beginning and at the end of the reference period (1 May-26 June 2002, see Fig. 14).

The computed steady-state position of the groundwater level and the pore pressure profile are depicted in Fig. 15 with evidence of flow lines. Numerical results seem to preliminary confirm the shape and position of the hypotesised shallow aquifer related to the deep groundwater flow system (see Fig. 11).

The equivalent porosity and saturated hydraulic conductivity, which are very difficult to measure reliably, were then defined on the basis of a series of transient back analyses which were performed on the mesh depicted in Fig. 15 with reference to the 1 May-26 June 2002 period (see Fig. 14).

Figures 16 and 17 show the measured and computed evolution of the transient pore pressure in response to the heavy measured rainfall, varying the saturated hydraulic conductivity and the porosity, respectively.

The comparison between the computed pore pressure curves in Fig. 16 shows that a change of the hydraulic conductivity of the porous matrix has an important effect on both the time-lag between the beginning of infiltration phenomena and the first pore pressure increment and the maximum pore pressure peak. Hence, the hydraulic conductivity influences both the shape and the time response of the computed pore pressure curve.

Starting from a benchmark value of $8 \times 10^{-5} \mathrm{~m} \mathrm{~s}^{-1}$, a $75 \%$-decrease of the hydraulic conductivity $\left(2 \times 10^{-5} \mathrm{~m} \mathrm{~s}^{-1}\right)$ roughly corresponds to a $50 \%$-decrease of the reactivity of the system and to an extra pore pressure increase of about $13 \%$. On the opposite, an increase of the hydraulic conductivity by a factor of 10 roughly corresponds to a $100 \%$-increase of the reactivity of the system and to an underestimation of $40 \%$ of the pore pressure peak.

Modelling results show that if the hydraulic conductivity is greater than $4 \times 10^{-4} \mathrm{~m} \mathrm{~s}^{-1}$, the response of the computed pore pressure is too fast and too underestimated, whereas if it is lower than $2 \times 10^{-4} \mathrm{~m} \mathrm{~s}^{-1}$, the computed pore pressure are too elevated and react too late. It must be pointed out that for low values of the hydraulic conductivity, the system doesn't return to its initial steady-state condition within the reference period.

On the other side, the effect of different porosities on the hydraulic response of the two-dimensional plain strain model of the landslide is highlighted by comparing the pore pressure curves in Fig. 17: the role of porosity during the infiltration process clearly drives both the pore pressure peak and the time-lag between the beginning of the rainfall event and the starting of the pore pressure increase.

Therefore, the change of the porosity implies both a variation of the shape of the transient pore pressure curve and the delay effect. The investigated range of porosities is from very high values $(40-50 \%)$ to very low values $(1 \%-$ $2 \%$ ), and results in high variations of the transient computed pore pressure fluctuations. Starting from a benchmark value of $5 \%$, a decrease of the porosity by a factor of 5 roughly corresponds to an extra pore pressure increase of about $31 \%$ and to a $100 \%$ increase of the reactivity of the system. On the opposite, an increase of the porosity by a factor of 10 roughly corresponds to a $75 \%$-decrease of the reactivity of the system and to an underestimation of $35 \%$ of the pore pressure peak. 


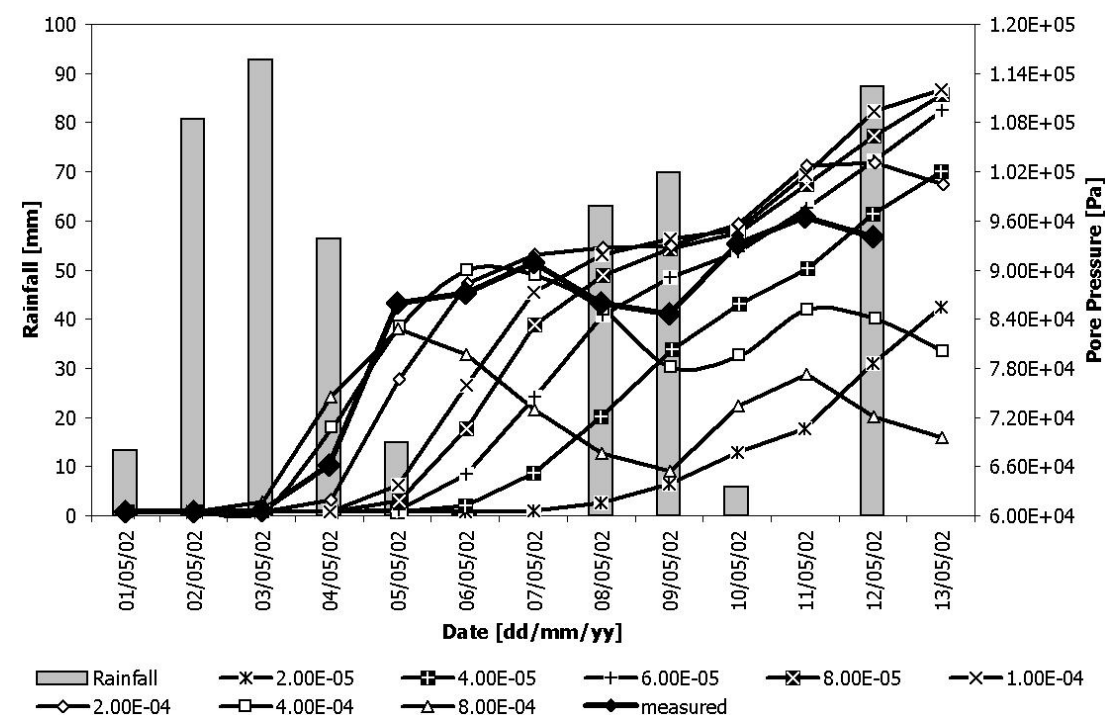

Fig. 16. Comparison between the measured and computed pore pressure, varying the saturated hydraulic conductivity: assumed porosity of $6 \%$.

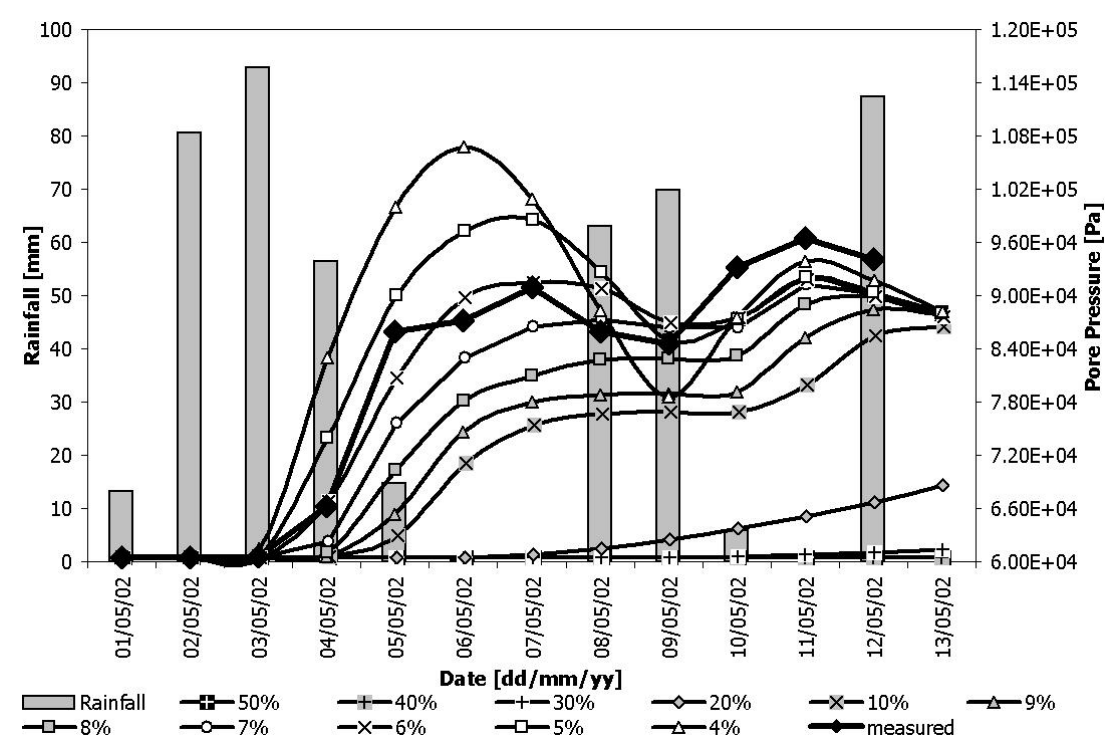

Fig. 17. Comparison between the measured and computed pore pressure, varying the porosity: assumed saturated hydraulic conductivity of $3 \times 10^{-4} \mathrm{~m} \mathrm{~s}^{-1}$.

Numerical results shows that porosities greater than $7 \%$ and lower than $5 \%$ imply computed pore pressure increases too underestimated or too precautionary and reaction times too dilated or too contracted, respectively.

Even though some differences, linked to the lowering of the water table, were highlighted after wet periods of some days, the best fit solution indicated that the suitable ranges of back analysed hydraulic conductivities and porosities were from $2 \times 10^{-4}$ to $4 \times 10^{-4} \mathrm{~m} \mathrm{~s}^{-1}$ and from $5 \%$ to $7 \%$, respectively.

\section{Conclusions and further developments}

A study has been presented on the hydro-mechanical aspects of a large deep seated instability phenomena that has been occurring at Rosone, in the Orco Valley (Italian western Alps) and which has been affecting some villages, a national road and a hydroelectric power plant.

The presence of a failure zone at an advanced stage of evolution can be inferred from the results of the many geomechanical investigations that have been carried out since 1929. This failure zone seems to be the reactivation of a preexistent shear band. 
The hypothesis of a sliding mechanism, driven by the variation in water pressure inside the massif, has been proposed on the basis of the large amount of information available on the geostructural and geomechanical features of the massif and on the basis of the results of a monitoring system located in the most active sector of the landslide. The validation of this hypothesis requires a detailed hydrogeological model of the landslide, the definition of which has been described in the paper.

The observed structural characteristics, inclinometric and piezometric measurements, stratigraphic profiles, seismic imaging, geomorphological remarks and hydraulic conditions (in terms of global water balance, chemical analyses, and census of the springs draining the slope), have allowed us to hypothesise the presence of two separate aquifers, bordered by two differently evolved shear bands, assumed as impervious layers.

A first set of numerical analyses has been performed to back analyze the key hydraulic parameters of the rock mass and to simulate the change in the water table level with time during intense rainfall. The best fit results indicate that the back analysed hydraulic conductivity and porosity ranges are from $2 \times 10^{-4}$ to $4 \times 10^{-4} \mathrm{~m} \mathrm{~s}^{-1}$ and from $5 \%$ to $7 \%$, respectively, even though some difficulties related to the unloading branch of the transient water pore pressure curve after a rainfall event have been highlighted.

The further developments of the numerical aspect of this study will be the complete hydromechanical simulation of the landslide with the aims of both back calculating the equivalent mechanical properties of the rock mass and comparing the computed displacements to the recorded ones.

This aspect will be the main object of future investigations on the landslide behaviour, which will be aimed at supplying an additional tool, based on hydromechanical numerical analyses, to understand the involved mechanisms. This could allow us to predict the future behaviour of the landslide for civil protection purposes. However, since systematic monitoring campaigns on the hydrology of the slope began only in 2008, some specific additional field investigations seem necessary to sustain the hydrogeological model of the Rosone landslide. The confirmation of the hypothesis of two different aquifers at different depths (and of the hydraulic conductivity) could be investigated by tracer tests to check the path of flowing water within the rock mass and by the installation of new piezometers on and off the landslide body, whose presence will be useful to understand the three-dimensional shape of the water table in steady-state conditions as well as providing fundamental information about the spatial transient pore pressure variations during periods of intense rainfall.

Acknowledgements. The Authors wish to thank Yves Guglielmi and Bartolomeo Vigna for the stimulating discussions and precious hints, ARPA Piemonte and Regione Piemonte for their collaboration, and Francesco Calvetti for having helped to solve some fundamental numerical problems.
Edited by: T. Glade

Reviewed by: two anonymous referees

\section{References}

Bonnard, C., Forlati, F., and Scavia, C. (Eds.): The Rosone landslide, in: Identification and mitigation of large landslide risks in Europe, IMIRILAND Project, 89-136, 2004.

Barla, G. and Chiriotti, E.: Insights into the behaviour of the large deep-seated gravitational slope deformation of Rosone, in the Piemonte Region (Italy), Proc. 44th Geomechanics Colloquim, Salzburg, 425-432, 1995.

Binet, S., Mudry, J., Scavia, C., Campus, S., Bertrand, C., and Guglielmi, Y.: In situ characterization of flows in a fractured unstable slope, Geomorphology, 86(1), 193-203, 2007.

Careggio, C.: Analisi dei dati di monitoraggio della frana di Rosone in un'ottica di Protezione Civile, Specialistic Graduation Thesis, Department of Structural and Geotechnical Engineering, Politecnico di Torino, Torino, 2006 (in Italian).

Chiriotti, E.: Mathematical modelling of the behaviour of the large deep-seated gravitational slope deformation of Rosone, Dissertation, Department of Structural and Geotechnical Engineering, Politecnico di Torino, Torino, 1997.

Dal Piaz, G. V. and Lombardo, B.: Early Alpine eclogite metamorphism in the Penninic Monte Rosa - Gran Paradiso basement nappes of the northwestern Alps, Geol. Soc. Am. Mem., 164, 249-265, 1986.

Forlati, F., Ramasco, M., Susella, G., Barla, G., Marino, M., and Mortara, G.: La deformazione gravitativa di Rosone. Un approccio conoscitivo per la definizione di una metodologia di studio, in: Proc. Conference on "Fenomeni franosi. Interventi di salvaguardia del territorio e proposte per la pianificazione urbanistica", Riva del Garda, 23-25 May 1990, Studi Trentini di Scienze Naturali (Acta Geologica), 68, 71-108, 1991 (in Italian).

Forlati, F., Gioda, G., and Scavia, C.: Finite element analysis of a deep-seated slope deformation, Rock Mech. Rock Eng., 34, 135159, 2001.

Ramasco, M., Stoppa, T., and Susella, G.: La deformazione gravitativa profonda di Rosone in Valle Orco, Italian Journal of Geosciences, 108, 401-408, 1989 (in Italian).

Regione Piemonte and Universitè J. Fourier (Eds.): La frana di Rosone - Valle Orco, in: Rischi Generati da Grandi Movimenti Franosi, Programme INTERREG I Italy - France: 144-177, 1996 (in Italian).

Sacchi, E., Dematteis, A., and Rossetti, P.: Past and present circulation of $\mathrm{CO}_{2}$-bearing fluids in the crystalline Gran Paradiso Massif (Orco Valley, north-western Italian Alps): tectonic and geochemical constraints, Appl. Geochem., 19, 395-412, 2004.

S.G.I. - Studio Geotecnico Italiano: Frana di Rosone Modellazione numerica alle differenze finite del versante, in: Attività di progettazione, fornitura e installazione di un sistema di monitoraggio integrato del movimento franoso di Rosone, Internal Report, Azienda Energetica Metropolitana di Torino, 2001 (in Italian).

Turc, L.: Estimation of irrigation water requirements, potential evapotranspiration: A simple climatic formula evolved up to date, Ann. Agron., 12, 13-49, 1961. 